\title{
PROCEDIMENTOS METODOLÓGICOS PARA ANÁLISE DAS ILHAS DE CALOR EM CIDADES DE PEQUENO E MÉDIO PORTE
}

\author{
PORANGABA, Gislene Figueiredo Ortiz - gifortiz@gmail.com \\ Universidade Federal do Mato Grosso do Sul/UFMS-CPTL- Três Lagoas
}

TEIXEIRA, Danielle Cardozo Frasca - danielle.frasca@hotmail.com

Universidade Estadual Paulista Julio de Mesquita Filho/UNESP-Presidente

Prudente

AMORIM, Margarete Cristiane de Costa Trindade - mccta@fct.unesp.br

Universidade Estadual Paulista Julio de Mesquita Filho/UNESP-Presidente

Prudente

\begin{abstract}
RESUMO: No presente artigo apresentam-se técnicas de análises e representações de ilhas de calor, que são responsáveis pela queda da qualidade ambiental e pelo desconforto térmico da população urbana. Assim, foram abordadas as técnicas de mensuração da temperatura do ar através de pontos fixos e de transectos móveis, o tratamento de imagens de satélite para a análise da temperatura da superfície urbana, como também a modelização por meio de informações do uso da terra e da temperatura do ar. As técnicas apresentadas foram empregadas nas cidades de Cândido Mota (SP) e Rancharia (SP), como exemplos, podendo ser utilizadas em outras investigações acerca das ilhas de calor.
\end{abstract}

Palavras- chaves: ilhas de calor; pontos fixos; transectos móveis; temperatura de superfície; modelagem climática.

METHODOLOGICAL PROCEDURES FOR ANALYSIS OF HEAT ISLANDS IN SMALL AND MID-SIZED CITIES

ABSTRACT: In this article, analysis techniques and heat islands representations are presented, which are responsible for the reduction of environmental quality and the thermal discomfort of the urban population. Thus, the techniques of air temperature measurement, through fixed points and mobile transects, the treatment of satellite images for analyzing the temperature of the urban surface, as well as the modeling of heat island were approached, by means of the land use and air temperature information. The techniques presented were employed in the cities of Cândido Mota (SP) and Rancharia (SP) and can be used in other investigations concerning the heat islands.

Keywords: heat islands; fixed points; mobile transects; surface temperature; climate modeling.

\section{INTRODUÇÃO}

As cidades representam a forma mais radical de transformação da paisagem através da ação antrópica, que muitas vezes deixa de respeitar o ambiente natural para a construção de um ambiente artificial, mudando assim os condicionantes climáticos e ambientais (FERNÁNDEZ GARCÍA, 1996).

As modificações na superfície decorrentes da urbanização provocam problemas ambientais urbanos, como a potencialização das enchentes e inundações devido à retirada da cobertura vegetal e impermeabilização do solo, os deslizamentos de encostas por conta da ocupação desordenada e do desmatamento das vertentes, a poluição dos solos, rios e corpos freáticos decorrente da má destinação dos resíduos sólidos, a poluição atmosférica resultante da circulação de veículos e do lançamento de gases industriais. As 
alterações na atmosfera próxima da superfície aumentam a temperatura do ar, concentram as precipitações, diminuem a umidade relativa e alteram a velocidade e direção dos ventos, criando assim um novo clima local. Esse novo clima local é definido por Monteiro (1976, p. 95) como o clima urbano sendo "um sistema que abrange o clima de um dado espaço terrestre e sua urbanização".

Dentre os efeitos do clima urbano as ilhas de calor são as mais percebidas pela população urbana, por estarem diretamente ligadas ao campo de percepção humana e influenciarem até mesmo no desempenho físico e atividades do dia a dia, como em casos mais graves na saúde das pessoas. As "ilhas de calor são formadas em áreas urbanas e suburbanas porque muitos materiais de construção comuns absorvem e retêm mais a radiação solar do que os materiais naturais em áreas rurais ou menos urbanizadas" (GARTLAND, 2010, p. 9).

As ilhas de calor causam desconforto térmico e podem agravar alguns problemas de saúde, assim é necessário que se façam diagnósticos das mesmas para indicar possíveis medidas mitigadoras, com a finalidade de amenizar seus efeitos no ambiente urbano e consequentemente na qualidade de vida da população atingida. Tais diagnósticos são realizados pela comunidade científica através de procedimentos metodológicos adequados para a análise das ilhas de calor. Nesse sentido, no presente trabalho o objetivo é demonstrar procedimentos metodológicos utilizados para o diagnóstico e análise do clima urbano na escala local, mais especificamente das ilhas de calor, em cidades de pequeno e médio porte, tendo como exemplo cidades do interior do estado de São Paulo.

Investigações acerca das ilhas de calor em cidades de pequeno e médio porte têm detectado a manifestação do fenômeno em grandes magnitudes, criando situações de desconforto térmico no ambiente tropical que naturalmente produzem desconforto pelo calor (MENDONÇA, 1994; PITTON, 1997; AMORIM, 2000, 2005, 2010; ORTIZ, 2012; UGEDA JUNIOR, 2012; FRASCA TEIXEIRA, 2015; ORTIZ PORANGABA, 2015).

Segundo dados do IBGE $^{1}$, a década de 1940 evidencia a tardia urbanização brasileira que, à época, contabilizava $31,24 \%$ da população urbana. A partir de 1970 , mais da metade da população brasileira $(55,92 \%)$ já residia na área urbana, aumentando em ritmo acelerado nas décadas seguintes. Em 2010, 84,36\% da população brasileira estava fixada nas cidades. Em face à rápida urbanização, o Brasil, assim como outros países da América Latina, experimentou uma urbanização não planejada adequadamente, geradora de inúmeros problemas de ordem ambiental, social e econômica.

As elevadas concentrações populacionais em núcleos urbanos, atraídas inicialmente por uma melhoria na qualidade de vida, obrigaram a uma progressiva maximização da utilização do espaço urbano, relativamente às funções que lhe são

\footnotetext{
${ }^{1}$ Disponível em:

http://seriesestatisticas.ibge.gov.br/series.aspx?vcodigo=POP122\&sv =33\&t=taxa-urbanizacao $>$ Acesso em: 13 jan. 2014.
} 
destinadas: transformação da matéria-prima, inovação tecnológica, transporte, educação e dinamização sócio-cultural. o homem (sob o ponto de vista físico e psico-social) e o espaço foram os maiores perdedores nesse processo, de crescimento desenfreado, dos núcleos urbanos. A procura de constantes feedbacks positivos, gerou distúrbios no equilíbrio do Ecossistema e alterou o valor de cada um dos elementos do sistema, favorecendo uns em detrimento de outros (MONTEIRO, 1997, p. 16, grifos das autoras).

A urbanização tardia e sem adequado planejamento foi comum às cidades de todos os portes e graus de urbanização, contudo, e evidentemente, nas maiores aglomerações urbanas os problemas causados pelo uso inadequado dos espaços intraurbanos, em que se considerem as potencialidades do meio físico, se tornaram mais impactantes. Mas, mesmo as cidades de médio e pequeno porte têm apresentado problemas ambientais e sociais que refletem no comprometimento da qualidade de vida do homem urbano e o clima é "um importante indicador de qualidade ambiental urbana e de qualidade de vida da população" (AMORIM, 2012, p. 78).

Assim, serão apresentadas as técnicas de mensuração da temperatura e as suas formas de representação e espacialização, sendo os pontos fixos e os transectos móveis para a tomada da temperatura do ar, o tratamento de imagens de satélite para o diagnóstico da temperatura superficial urbana e a modelagem climática que utiliza informações do uso da terra e da temperatura do ar.

\section{MENSURAÇÃO DA TEMPERATURA DO AR ATRAVÉS DE PONTOS FIXOS}

As mensurações de temperatura do ar através de pontos fixos devem observar detalhadamente o local de instalação dos equipamentos de aferição dos dados. De acordo com Oke (2004), as estações meteorológicas devem ser instaladas em áreas representativas do meio que se quer analisar. Desta forma, recomenda-se que as estações sejam colocadas em espaços abertos com aspectos similares de seu entorno. Ainda com base em Oke (op. cit.) a padronização das estações meteorológicas instaladas em áreas com grama curta e locais abertos representa uma condição rural modificada e não uma paisagem urbana.

As estações meteorológicas devem ser protegidas da incidência direta dos raios solares, podendo ser alojadas em miniabrigos meteorológicos, normalmente feitos de madeira, com parede dupla e perfurada, com a porta voltada para o sul (se instalado no hemisfério sul, devido o menor recebimento de radiação nesse quadrante), com distância de 1,5 a $2 \mathrm{~m}$ da superfície (Figura 1). Desta forma, as estações meteorológicas devem ser programadas para coletarem os dados conforme o objetivo da pesquisa, como por exemplo, aferição da temperatura do ar a cada hora. 


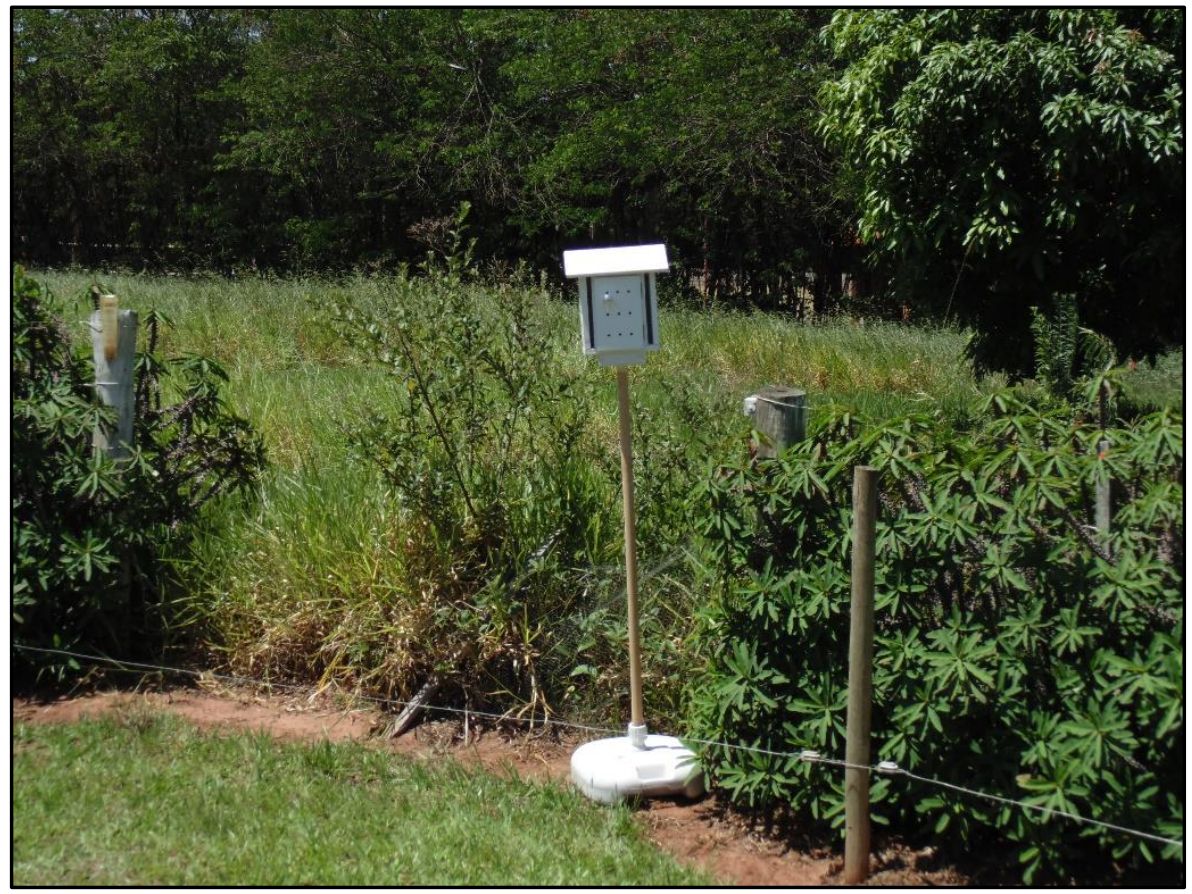

Figura 1 - Abrigo meteorológico instalado em área rural do município de Rancharia (SP). Fonte da foto: trabalho de campo (2014).

A partir da obtenção dos dados meteorológicos é possível dar um tratamento para a representação da realidade pesquisada, quanto mais pontos de mensuração forem instalados, melhores serão os resultados. Os dados referentes à temperatura do ar podem ser representados em gráficos, mapas e painéis, dependendo do objetivo da pesquisa.

\subsection{PAINÉIS ESPAÇOTEMPORAIS ELABORADOS A PARTIR DE DADOS DE PONTOS FIXOS}

Uma das formas de apresentação dos dados de clima, os painéis espaçotemporais (Figura 2 ) são representações gráficas que mostram a variação de um fenômeno climático no tempo e sua projeção em um eixo espacial (SANT'ANNA NETO, 1990; ARAÚJO, 2001; BRANDÃO, 2003). Dependendo do objetivo do trabalho esse produto pode exibir uma informação geográfica e conter ou não uma espacialização.

Os painéis demonstram linhas de igual valor, as isolinhas. Um eixo representa o tempo e outro exibe a projeção do fenômeno no espaço. Na figura 2 é possível analisar as diferenças térmicas apresentadas pelos pontos, identificando as áreas que potencialmente configuraram ilhas de calor. $O$ recorte territorial da pesquisa refere-se à Rancharia (SP) e o monitoramento ocorreu às 21 horas durante os 31 dias de janeiro de 2014. 


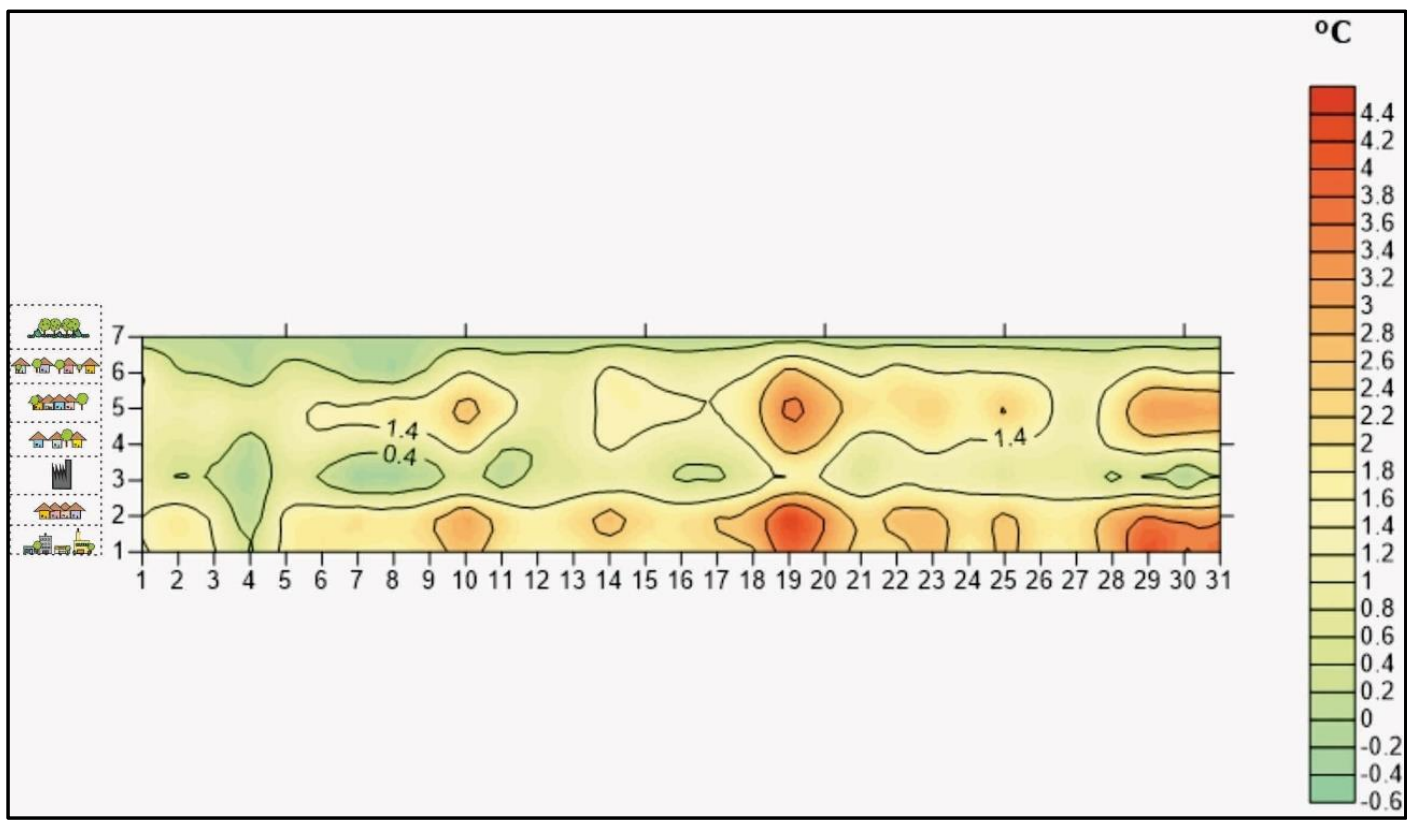

Figura 2 - Diferença térmica registrada às 21 horas através de pontos fixos em Rancharia (SP) em janeiro de 2014. Fonte dos dados: Trabalho de campo (2014). Elaboração: das autoras.

No exemplo destacado, o eixo horizontal representa o período da observação (mês de janeiro de 2014) e o eixo vertical demonstra os pontos fixos que foram instalados em diferentes lugares representativos das feições urbanas.

Os pontos urbanos, numerados de 1 a 6 , foram comparados com um ponto de controle rural (ponto 7). A partir do trabalho em planilhas do aplicativo Excel ${ }^{2}$, foi possível obter os gradientes térmicos registrados em cada ponto fixo. De posse dos gradientes térmicos, os dados foram plotados gerando um grid (grade) de informações com a Krigagem como interpolador.

A análise destes dados foi amparada pela análise rítmica, permitindo relacionar a ocorrência da ilha de calor com sistemas atmosféricos que atuaram durante o monitoramento.

À noite, os pontos intraurbanos, com exceção do ponto 3, mostraram intensidades de até $+4,5^{\circ} \mathrm{C}$. As diferenças térmicas estiveram distribuídas durante o mês de janeiro, com destaque, sobretudo, nos pontos de maior densidade construtiva como no caso do ponto 5 que trata-se de um conjunto habitacional, ponto 6 (bairro residencial vila Teresa, área densamente construída, lotes maiores e arborizados), além dos ponto 1 e 2 situados no centro (área densamente construída).

Às 21 horas, destacou-se o ponto 1 , no centro urbano de Rancharia que configurou uma ilha de calor de forte magnitude (FERNÁNDEZ GARCÍA, 1996), marcando $+4,5^{\circ} \mathrm{C}$ no dia 29 de janeiro. A amplitude térmica situou-se entre $+0,3^{\circ} \mathrm{C}$ e $+4,5^{\circ} \mathrm{C}$, demonstrando que neste horário esteve mais aquecido do que o rural. Os episódios com os maiores gradientes ocorreram na atuação

\footnotetext{
${ }^{2}$ Excel é marca registrada da Microsoft Corporation.
} 
de sistemas estáveis como a massa Polar Tropicalizada e a massa Tropical Atlântica.

Em resumo, pode-se afirmar que a representação dos fenômenos climáticos, como a ilha de calor por meio dos painéis espaçotemporais constituem uma alternativa para sintetizar os dados e interpretar a informação geográfica, que no estudo de caso demonstrado pretendia a identificação das diferenças térmicas entre os pontos. No entanto, neste tipo de tratamento não ocorreu a espacialização da ilha de calor, que pode ser realizada através do cruzamento dos pontos de registro da intensidade ou dos valores absolutos da temperatura do ar com a planta georreferenciada da cidade visando a elaboração de cartas de isotermas. Estes processamentos podem ser realizados no programa Surfer ${ }^{3}$.

\section{MENSURAÇÃO DA TEMPERATURA DO AR POR MEIO DE TRANSECTOS MÓVEIS}

O transecto móvel é uma técnica muito utilizada pela comunidade científica de climatologia (LÓPEZ GÓMEZ E FERNÁNDEZ GARCÍA, 1993; PITTON, 1997; AMORIM, 2005; UGEDA JÚNIOR, 2012; FRASCA TEIXEIRA, 2015; ORTIZ PORANGABA 2015), para o diagnóstico das ilhas de calor. Consiste na coleta de temperatura do ar a partir de medidas móveis, podendo ser realizada a pé, de bicicleta ou de veículos automotores (OKE, op. cit), perpassando pelas diferentes áreas de interesse para a verificação de alterações térmicas. O melhor horário para a realização do procedimento é após o pôr do sol, pois é neste momento que a estrutura urbana tem o pico de liberação de calor armazenado durante o dia, demonstrando assim quais os pontos urbanos se aquecem mais e/ou formam ilhas de calor (OKE, op. cit).

Os transectos através de veículos automotores devem transitar a baixa velocidade, tendo o sensor de temperatura instalado na sua lateral em uma haste de madeira (Figura 3). O tempo máximo entre o início e o final das mensurações deve ser de uma hora, para se evitar que a atmosfera urbana sofra alterações meteorológicas naturais que possam comprometer os resultados. Mesmo assim, é muito importante que se faça o monitoramento de possíveis diferenças entre o tempo de início e de conclusão do percurso em um ponto fixo.

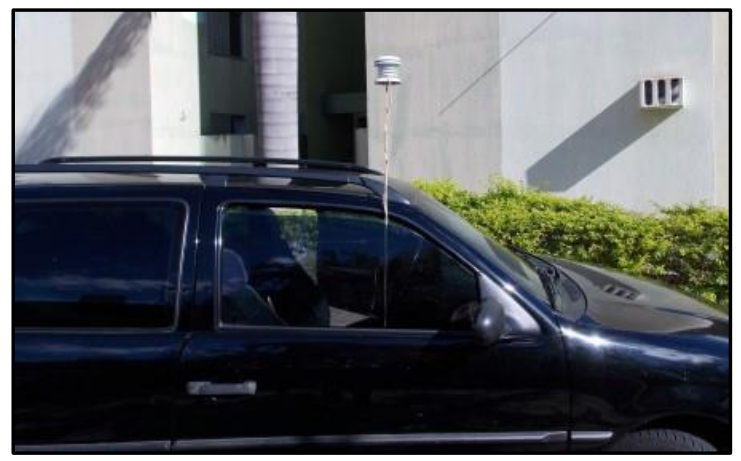

Figura 3 - automóvel equipado com sensor de temperatura

\footnotetext{
${ }^{3}$ Surfer é marca registrada da Golden Software.
} 
A estabilidade da atmosfera (ausência de precipitação e de ventos) é um fator importante para a realização do procedimento, porque a instabilidade da mesma faz com que a temperatura do ar se homogenize, impedindo o diagnóstico das áreas mais aquecidas da cidade.

O trajeto para os transectos móveis deve ser selecionado objetivando a cobertura das diferentes formas de uso e ocupação da superfície urbana, partindo do rural percorrendo a cidade e finalizando no rural.

A limitação desse procedimento se deve ao fato da aquisição dos dados ocorrer apenas nos episódios de mensuração, não tendo assim um monitoramento temporal contínuo da área estudada, como ocorre nos pontos fixos. Entretanto, o detalhamento da condição atmosférica urbana é mais refinado por conseguir mensurar mais pontos durante o trabalho de campo.

\subsection{REPRESENTAÇÕES DOS DADOS CLIMATOLÓGICOS OBTIDOS POR TRANSECTOS MÓVEIS}

O tratamento dos dados em climatologia tem evoluído nas últimas décadas em virtude dos SIGs (Sistemas de Informação Geográfica). Os desafios que se colocam frente ao tratamento dos dados de fina escala referem-se à sua representação, pois o conhecimento real do clima local fica prejudicado em virtude da interpolação dos dados. Portanto, há de se ter em vista a ideal aquisição de dados primários e os objetivos do trabalho do que se pretende representar.

As ferramentas estatísticas e geoestatísticas dos SIGs enriquecem o tratamento dos dados, conferindo ao trabalho maior confiabilidade e uma análise mais robusta dos dados nos aspectos qualitativo e quantitativo.

Frequentemente presente nos trabalhos de climatologia, a Krigagem tem sido uma das principais ferramentas estatísticas utilizadas no tratamento dos dados climatológicos. Segundo Yamamoto e Landim (2013, p. 55), "a Krigagem é um processo geoestatístico de estimativa de valores de variáveis distribuídas no espaço e/ou tempo, com base em valores adjacentes quando considerados interdependentes pela análise variográfica". Está no grupo dos estimadores sendo que o mais usual é chamado krigagem ordinária.

Suas aplicações nos trabalhos de climatologia resultam em mapas que exibem isolinhas, que são linhas que conectam pontos de igual valor. A Figura 4 exibe um episódio da ilha de calor noturna detectada a partir de sete pontos fixos distribuídos em diferentes feições urbanas e de transecto móvel que atravessou de oeste a leste e de norte a sul avenidas e ruas adjacentes de Rancharia (SP), localizada no oeste do estado de São Paulo. O transecto móvel contou com 65 pontos de registro e aquisição dos dados se deu em 29 de janeiro de 2014.

Os registros destes dados primários da temperatura do ar foram organizados em planilhas do aplicativo Excel, que permitiu a obtenção do maior e do menor valor do percurso com fórmulas específicas do aplicativo, cujos resultados geraram a intensidade da ilha de calor a partir da subtração do valor medido em cada ponto pelo menor valor registrado no percurso (FERNÁNDEZ GARCÍA, 1996). 
Para a espacialização dos gradientes térmicos foi feito o cruzamento dos pontos de registro da intensidade com a planta georreferenciada da cidade

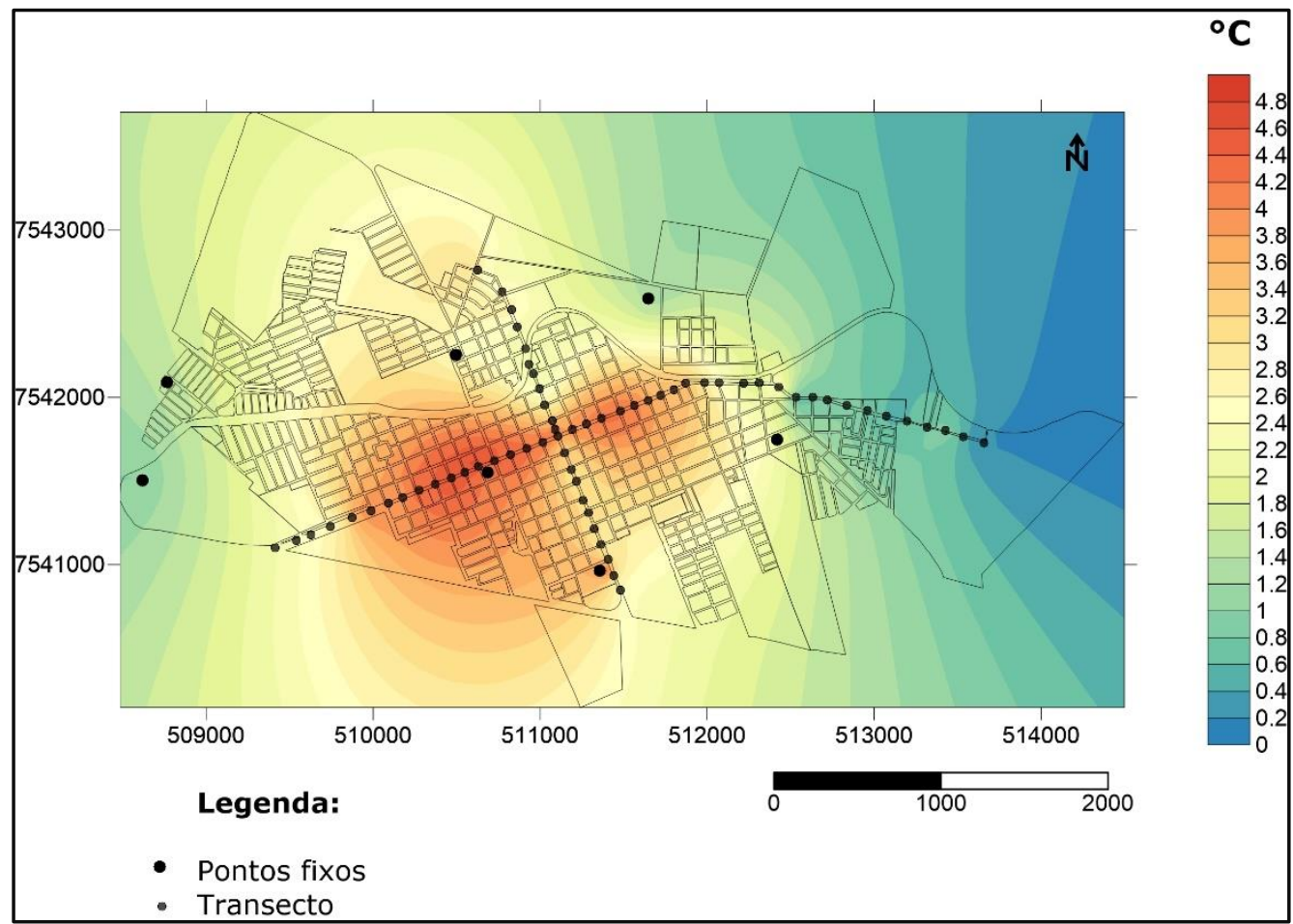

Figura 4 - Carta de isotermas de Rancharia (SP), 29 de janeiro de 2014, às 21 horas.

Observa-se que a ilha de calor atingiu a intensidade de $4,8^{\circ} \mathrm{C}$ na interseção dos percursos do transecto, coincidindo com a área central densamente edificada de Rancharia. No rural próximo, nas áreas mais distantes dos pontos de registro a temperatura é estimada através da interpolação dos dados e, portanto, possuem reduzida confiabilidade, visto que em Geoestatística:

Trabalha-se com funções locais, pois ela é por excelência um método local de estimativa. Nesse sentido, pontos distantes situados além do alcance do variograma não deveriam ser considerados, mas a krigagem tem um mecanismo interno de atenuação da influência destes pontos e, portanto, podem ser deixados como pertencentes à vizinhança (YAMAMOTO e LANDIM, 2013. p.56).

Uma das críticas feitas a esta forma de representação diz respeito às generalizações provocadas nas áreas onde não existiram a aquisição dos dados e por esse motivo, a sua confiabilidade fica restrita aos pontos onde se tem registro de dados. Portanto, um volume de dados maior pode beneficiar o procedimento.

Outra alternativa de representação dos dados mensurados através de medidas móveis é o perfil longitudinal, que visa relacionar as características 
urbanas, ou seja, o uso e a ocupação da superfície urbana e periurbana, com os dados obtidos em campo para assim diminuir a generalização das cartas de isotermas. O perfil longitudinal é composto por um gráfico com dados de temperatura do ar ou da intensidade da ilha de calor e representações das feições urbanas de cada ponto de coleta.

Com base na figura 5 , é possível observar que a intensidade máxima da ilha de calor em Cândido Mota em 17 de julho de 2013 às $06 \mathrm{~h}$, foi de $4,9^{\circ} \mathrm{C}$ no ponto 22, área densamente construída e com vegetação arbórea esparsa. Os pontos de 1 a 3, ambiente de transição entre o rural e o urbano, foram os que apresentaram menor aquecimento. No mesmo dia às $21 \mathrm{~h}$, na cidade de Cândido Mota, foi encontrada a maior intensidade de ilha de calor da presente investigação, sendo de $6,7^{\circ} \mathrm{C}$ no ponto 22 , onde se tem uma área densamente construída e com vegetação arbórea esparsa. Dos pontos 1 ao 3, a atmosfera urbana se apresentou mais fresca. Desta forma, o uso e a ocupação da terra se apresentou como fator de aquecimento da atmosfera urbana, pois onde se tem maior densidade construtiva na cidade ocorreu a maior intensidade de ilha de calor.

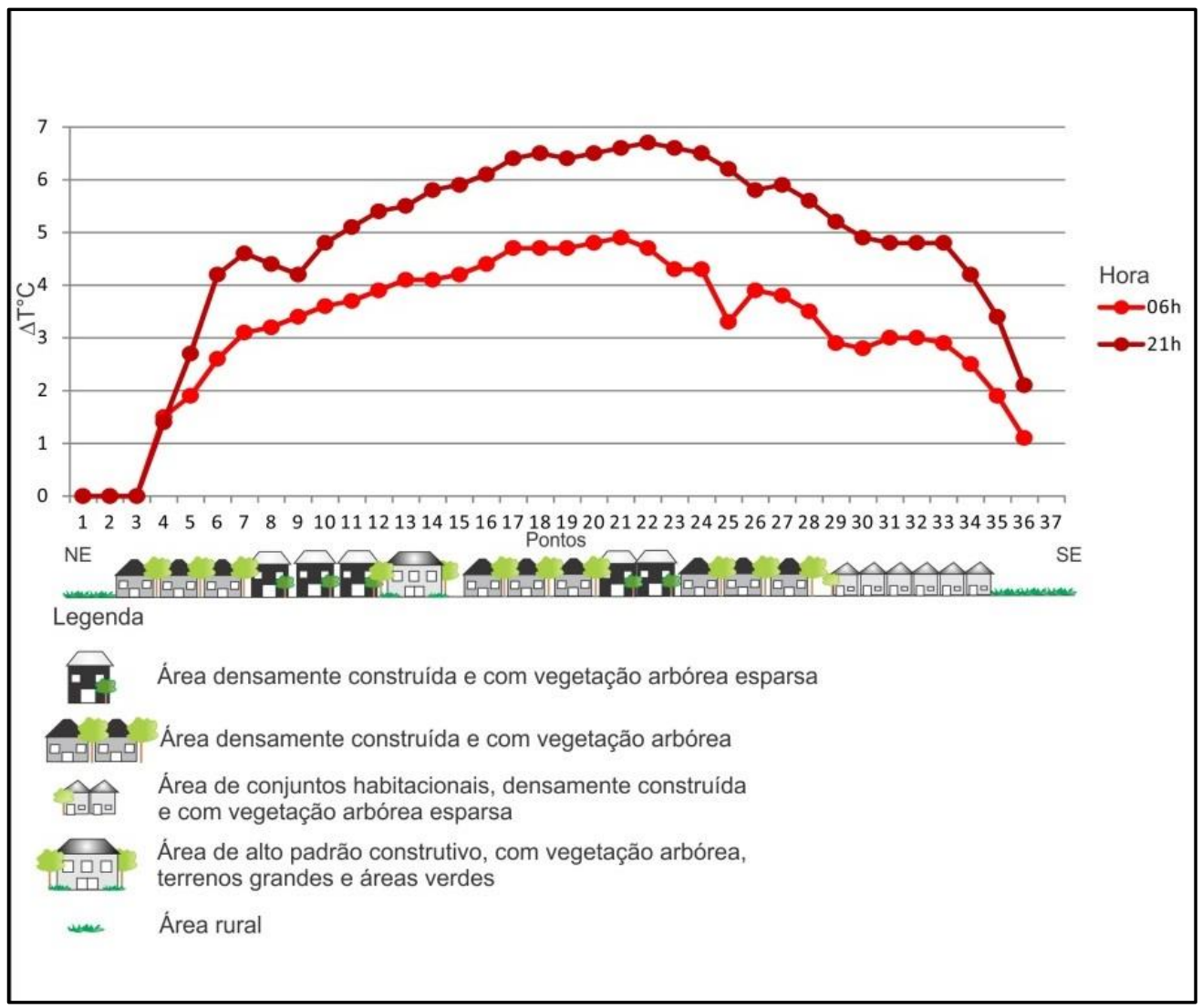

Figura 5 - Perfil longitudinal de Cândido Mota - 17/07/2013 - 6 e 21h 


\section{A TEMPERATURA SUPERFICIAL URBANA A PARTIR DE IMAGENS DE SATÉLITE}

O desenvolvimento das geotecnologias vem crescendo dia a dia, tornando-se importante aliada nas análises ambientais. Dentre as diferentes possibilidades de técnicas de análise das características do clima urbano em uma determinada cidade, pode-se utilizar os produtos gerados por meio de sensoriamento remoto. Trabalhos nesta perspectiva atualmente são mais acessíveis a pesquisadores de diversos países, incluindo os subdesenvolvidos. Também apresentam viabilidade financeira dado o baixo custo para a aquisição das imagens. Entretanto, esbarram na questão das resoluções temporal e espacial dos satélites e na presença de coberturas de nuvens para um monitoramento contínuo, sistemático e que atinja os objetivos do estudo.

No sensoriamento remoto, os objetos que tem temperatura acima do zero absoluto emitem energia eletromagnética. Portanto, todas as feições que encontramos cotidianamente na paisagem e pessoas emitem energia eletromagnética infravermelha termal. A energia captada pelos sensores instalados em aviões ou em satélites trazem informações acerca do alvo, que podem ser interpretadas, após o processamento digital da imagem, e assim apontar as reais condições do objeto analisado. Sob esta perspectiva, Jensen (2009) discorre sobre estudos que avaliaram a temperatura da superfície de diversas cidades através de sensoriamento remoto no infravermelho termal. De um modo geral, durante o dia observaram-se temperaturas mais elevadas em áreas comerciais, de serviços, transporte e industriais. Os menores valores de temperatura nesse mesmo período do dia ocorrem em corpos d'água, áreas com vegetação e terras agrícolas. As temperaturas intermediárias resultam de áreas de uso residencial, devido à mistura de diferentes elementos da paisagem urbana. Ao anoitecer as áreas que se encontravam mais aquecidas durante o dia se esfriaram rapidamente, mas ao amanhecer continuaram mais aquecidas que as áreas com vegetação e agrícolas.

São as diferenças de temperatura da superfície urbana que formam o clima urbano e as ilhas de calor, que "são causadas pelo desflorestamento e substituição da superfície do solo por materiais não evaporativos e não porosos, como asfalto e concreto" (JENSEN, 2009, p. 288). A identificação das áreas mais aquecidas e que potencializam a formação de ilhas de calor é de crucial importância para a análise do clima urbano, uma vez que a interação da atmosfera com essas superfícies urbanizadas produzem ambientes termicamente desagradáveis.

Nesse sentido, para a elaboração da carta de temperatura de superfície apresentada nesse trabalho, utilizou-se imagens do satélite Landsat 8 , banda 10 do infravermelho termal/TIRS 1 , com resolução espectral de 10.6 - 11.19 um (micrômetro), e resolução espacial de 100 metros, mas tratadas e disponibilizadas com pixel de 30 metros pela United States Geological Survey (USGS), dos dias 21 de agosto de 2013 (condição de inverno) e 15 de janeiro de 2015 (condição de verão).

Para o tratamento da imagens de satélite os seus valores digitais foram transformados para temperatura em graus Celsius $\left({ }^{\circ} \mathrm{C}\right)$ no programa IDRISI ${ }^{4}$, "[...] com a utilização de parâmetros fixos de conversão de níveis de cinza das

\footnotetext{
${ }^{4}$ Marca registrada da Clark Labs.
} 
imagens (NC) para radiância, depois para temperatura absoluta e finalmente para graus Celsius $\left({ }^{\circ} \mathrm{C}\right.$ ) obtidos no site ${ }^{5}$ do satélite Landsat (NASA)" (LIMA; AMORIM, 2010, p. 05).

Para a obtenção das temperaturas das superfícies, de modo geral, deve-se cumprir a sequência:

- $\quad$ Os valores de níveis de cinza (NC) da imagem são primeiro convertidos para radiância espectral, por meio dos parâmetros de radiância calibração absoluta de pós-lançamento do sensor TM. Os valores de radiância espectral obtidos são, então, transformados em refletância aparente;

- A estimativa das temperaturas da superfície terrestre, em graus Kelvin, por radiometria, baseia-se nas Leis de Stefan-Boltzman e Lei de Plank. Com base nos valores estimados de emissividade obtêm-se a temperatura da superfície mediante a inversão da equação de Plank para corpos radiadores seletivos; e,

- Gera-se a grade de temperatura da superfície mediante a transformação de Kelvin para graus Celsius $\left({ }^{\circ} \mathrm{C}\right)$, subtraindo os valores de $\mathrm{T}$ de 273,15 (DUMKE 2007, p. 246).

No programa IDRISI criou-se um projeto para a importação das imagens de satélite do infravermelho termal - banda 10, convertendo os níveis de cinza para informações de radiância. As equações e parâmetros foram obtidos no sítio da USGS ${ }^{6}$ e serão apresentados a seguir.

Onde:

$$
\mathbf{L A}=\mathbf{M L Q c a l}+\mathbf{A L}
$$

$\mathrm{L} \lambda=$ Radiância do topo da atmosfera (Watts $/(\mathrm{m} 2 * \operatorname{srad} * \mu \mathrm{m}))$;

$\mathrm{ML}=$ Fator multiplicativo de redimensionamento de cada banda presente nos metadados (Radiance_Mult_Band_x, onde $x$ é o número da banda);

$\mathrm{AL}=$ Fator aditivo de redimensionamento de cada banda presente nos metadados (Radiance_Add_Band_x, onde x é o número da banda); (DN).

Qcal $=$ Valores de pixel quantificados e calibrados do produto padrão

Posteriormente, para a conversão dos valores digitais para temperatura kelvin aplicou-se a fórmula:

\footnotetext{
${ }^{5}$ Disponivel em: <http://landsat.usgs.gov/>.

${ }^{6}$ Esses procedimentos foram obtidos no sítio https://landsat.usgs.gov/Landsat8_Using_Product.php._Acesso em: 07 jun. 2016.
} 


$$
T=\frac{K 2}{\ln \left(\frac{K 1}{L_{\lambda}}+1\right)}
$$

onde:

$\mathrm{T}$ = temperutura efetiva registrada pelo sensor do satélite em Kelvin;

$\mathrm{K} 2$ = constante de calibração $2=1321.08$

$\mathrm{K} 1$ = constante de calibração $1=774.89$

$\mathrm{L}=$ radiância espectral em Watts / (metros quadrado *ster* $\mu \mathrm{m}$ )

Para converter Kelvin em graus Celsius $\left({ }^{\circ} \mathrm{C}\right)$, ainda no programa IDRISI subtraiu-se 273,15 dos valores de temperatura gerando a grade de temperatura de superfície. Assim, o raster elaborado foi importado para o programa ArcGis, a fim de se inserir a malha urbana e finalizar as cartas com as convenções cartográficas.

Após a elaboração das imagens é possível fazer uma análise das porções urbanas mais aquecidas e com a presença de ilhas de calor de superfície. Assim, conforme a Figura 6 é possível notar que durante o inverno em Cândido Mota a temperatura superficial da cidade esteve mais baixa, com máxima de $34^{\circ} \mathrm{C}$ em áreas de solo exposto e mínima de $24^{\circ} \mathrm{C}$ em áreas com significativa densidade de vegetação e corpos d'água. No verão a temperatura superficial máxima foi de $37,8^{\circ} \mathrm{C}$ no ambiente urbano e em áreas de solo exposto, a mínima se apresentou com $24^{\circ} \mathrm{C}$ no ambiente rural vegetado. As áreas verdes no ambiente intraurbano tiveram temperaturas mais amenas do que as áreas construídas, sendo próximas de $32^{\circ} \mathrm{C}$.

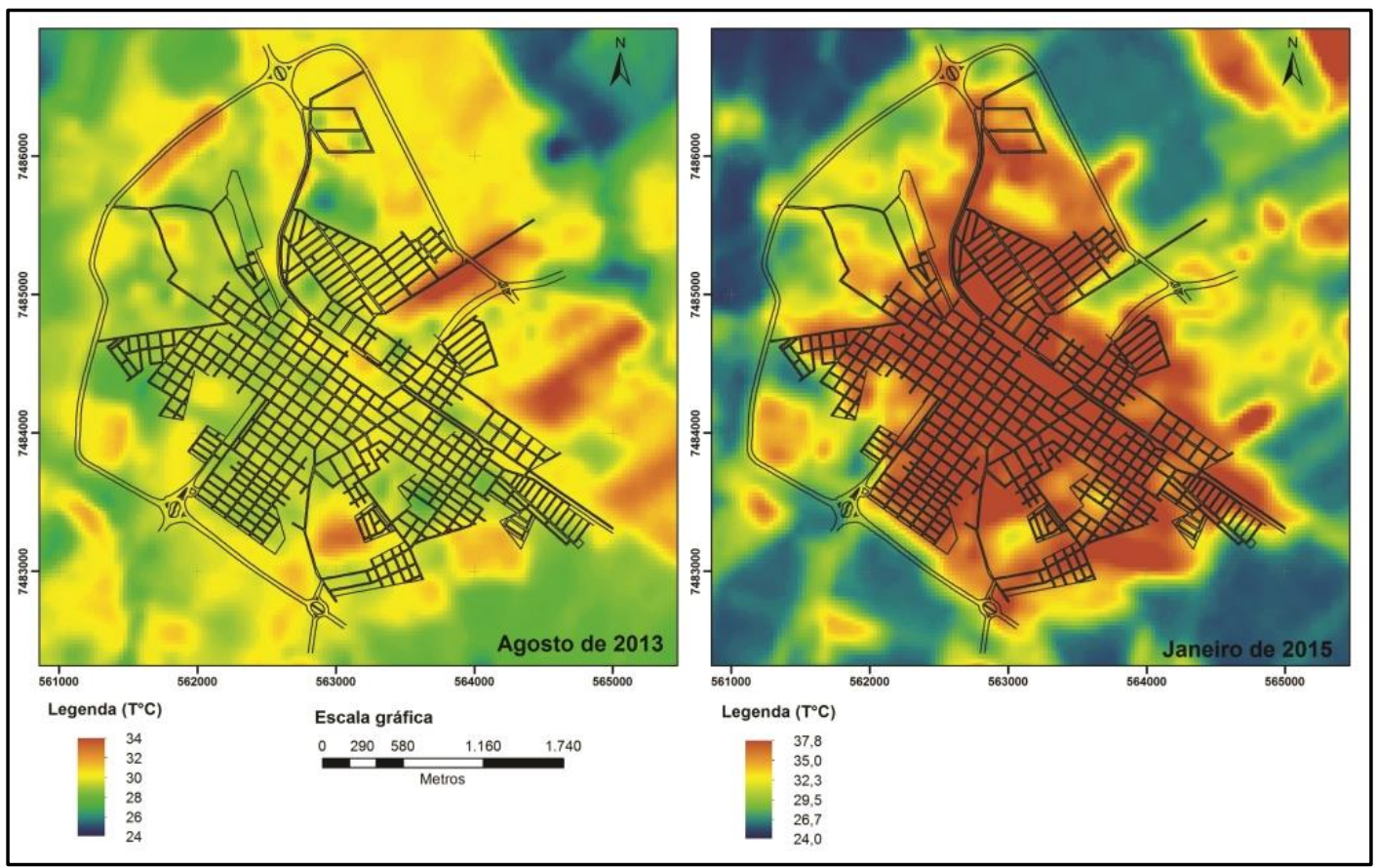


Figura 6 - Cartas de temperatura da superfície de Cândido Mota. Elaboradas com imagens do Landsat 8, banda 10, com resolução espacial de 30m, dos dias 21 de agosto de 2013 e 15 de janeiro de 2015 .

\section{MODELAGEM DA TEMPERATURA URBANA}

O diagnóstico da ilha de calor atmosférica se dá pelo registro da temperatura do ar próximo à superfície, seja por pontos fixos ou transecto móvel. O tratamento desses dados tradicionalmente tem sido direcionado à espacialização que tem a krigagem como técnica de interpolação, limitando as análises aos pontos onde se registrou dados. Neste sentido, vários autores vêm elaborando metodologias que se amparam nos SIGs para a interpolação dos dados de fina escala, incluindo informações como o relevo, a vegetação, as feições de superfície com o objetivo de obter maior detalhamento e confiabilidade na informação geográfica (KATZSCHNER, 2008; AMORIM et al., 2009; DUBREUIL et al., 2010; CARFAN, 2011; REN, et al., 2011; REN et al., 2012; FERREIRA, 2012; FOISSARD et al., 2013; FRASCA TEIXEIRA et al. 2015; AMORIM et al. 2015).

Para Lang e Blaschke (2009, p. 63), "a análise espacial apoiada em SIG objetiva fundamentalmente gerar novas informações, o que se dá por meio da manipulação e integração com camadas de dados já existentes". Baseado nisso, a modelagem da ilha de calor se caracteriza como uma nova metodologia com uma sequência de procedimentos para a espacialização da ilha de calor atmosférica integrando dados de registros em campo (transecto móvel e pontos fixos), imagem de satélite (utilizando-se para isso o Landsat 7 ou Landsat 8) e categorias de uso e ocupação da terra.

A modelagem sintetiza as informações pela relação estatística que é estabelecida com categorias de uso da terra a partir da regressão linear simples. Nesta regressão existe a relação entre uma variável dependente e outra independente:

As relações entre duas variáveis $X$, considerada independente, e $Y$, considerada dependente, podem ser representadas num diagrama de dispersão, com os valores de yi em ordenada e os de xi em abcissa. Cada par de valores xi e yi fornecerá um ponto e utilizando-se, por exemplo, o método dos desvios mínimos ao quadrado, pode-se calcular a equação de uma reta que melhor se ajuste à nuvem de distribuição. $O$ método mais comum que pode ser adotado é o da análise de regressão linear simples [...] (LOURENÇO e LANDIM, 2004, p. 2).

A temperatura do ar é entendida como uma variável dependente, enquanto que, as classes de uso da terra são consideradas variáveis independentes, ou seja, nesta relação entende-se que a temperatura do ar varia em função da feição do uso da terra em questão.

$\mathrm{Na}$ sequência, são apresentados os resultados da ilha de calor monitorada em Rancharia (SP) em evento de inverno por meio da modelagem que associa vários procedimentos no aplicativo IDRISI ${ }^{7}$.

\footnotetext{
${ }^{7}$ Idrisi é marca registrada da Clark Labs.
} 
Os dados primários de temperatura registrados em campo combinando rede meteorológica ${ }^{8}$ e transecto móvel ${ }^{9}$ foram tomados em lugares representativos do ambiente urbano e rural. Estes dados foram relacionados com categorias de uso da terra, obtidas a partir de classificação cluster. As feições de superfície identificadas, a saber: vegetação baixa, incluindo pastagens; área urbana; vegetação alta, que reúne cana-de-açúcar, eucalipto e arborização urbana, são exibidas na figura 7.

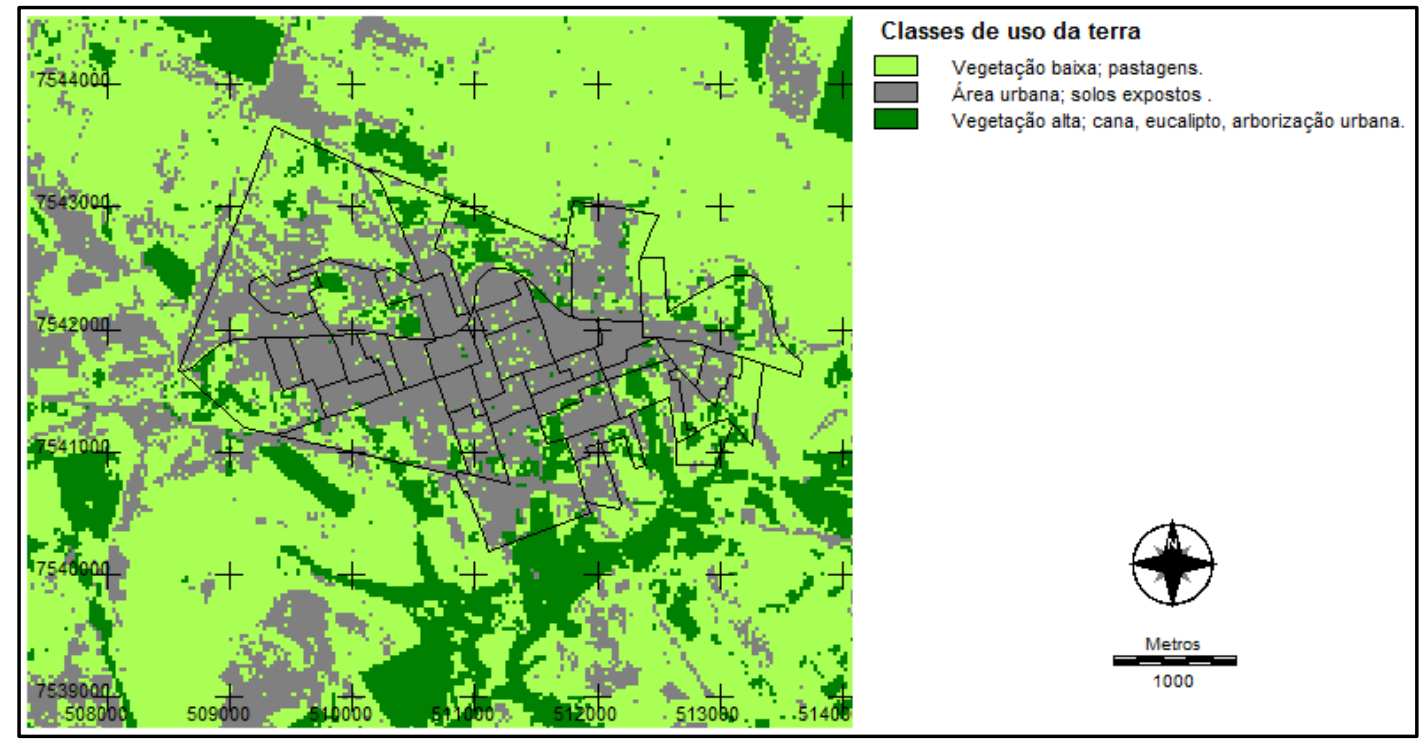

Figura 7: Carta de uso da terra, Rancharia (SP), elaborada com imagem Landsat 7, 15/07/ 2014, a partir do método cluster de classificação não-supervisionada. Fonte da imagem: <http://glovis.usgs.gov/> Elaboração: das autoras.

A partir das categorias da superfície são definidas as janelas de abrangência de um ponto de registro trabalhando-se em planilhas do programa Excel ${ }^{10}$ através de gráficos de dispersão que mostram individualmente os coeficientes de correlação entre as classes de uso da terra e a temperatura do ar (Quadro 1).

\footnotetext{
${ }^{8}$ Foram realizados registros através de rede meteorológica instalada no perímetro urbano de Rancharia em pontos representativos e um ponto de controle no rural circunvizinho, seguindo protocolos de OKE (2004). Sensores digitais (Humidity-temperature logger, da marca ThermaData ${ }^{T M}$ e do modelo HTD D104505072) foram depositados em miniabrigos meteorológicos e programados para registros horários da temperatura do ar, destacando-se às 21 horas para o monitoramento.

${ }^{9}$ Segundo Amorim (2005, p.69), "a metodologia para a coleta de temperatura do ar [...] consiste na definição de dois transectos, com medidas móveis, utilizando-se de termômetros digitais, com os sensores presos em haste de madeira com 1,5m de comprimento, acoplados na lateral de dois veículos que saem da periferia (rural), passando pelo centro, chegando ao extremo oposto da cidade.

${ }^{10}$ Excel é marca da Microsoft Corporation.
} 
Quadro 1: Frequência das categorias de uso da terra por pixel analisadas individualmente.

Frequência da classe 3(Vegetação alta) por pixel na janela 3×3 (90 x 90 metros).

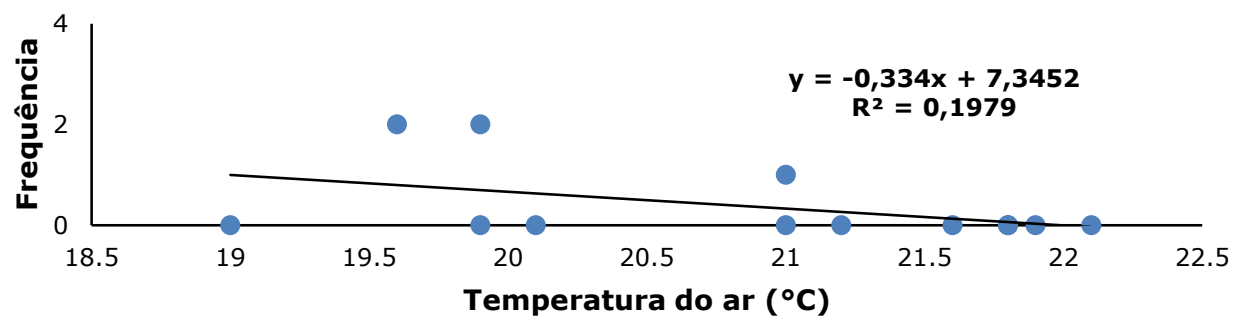

Frequência da classe 2 (urbana) por pixel na janela $5 \times 5$ (150 x 150 metros).

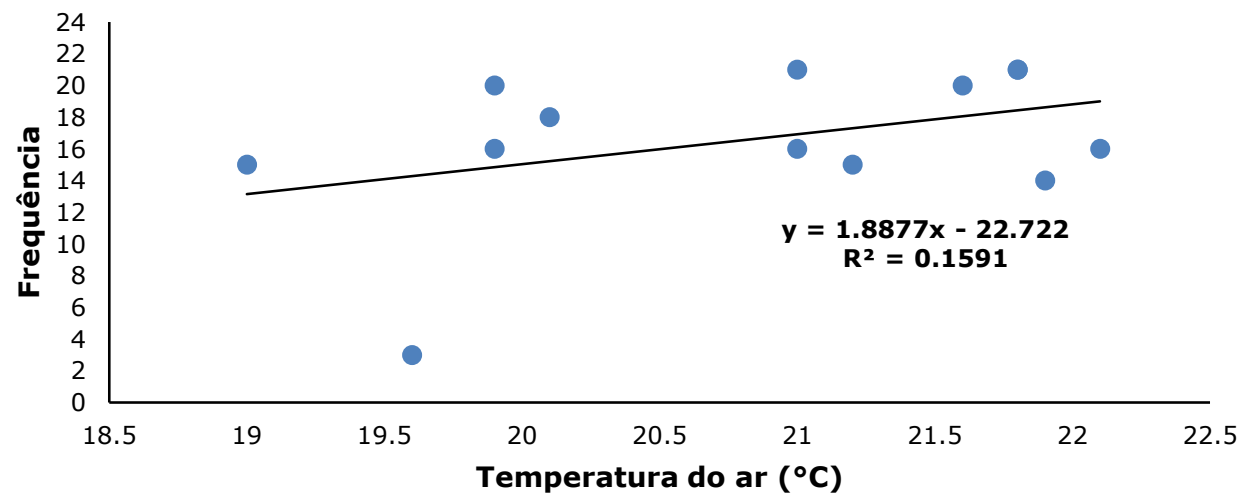

Frequência da classe 1 (vegetação baixa) por pixel na janela $7 \times 7$ ( $210 \times 210$ metros).

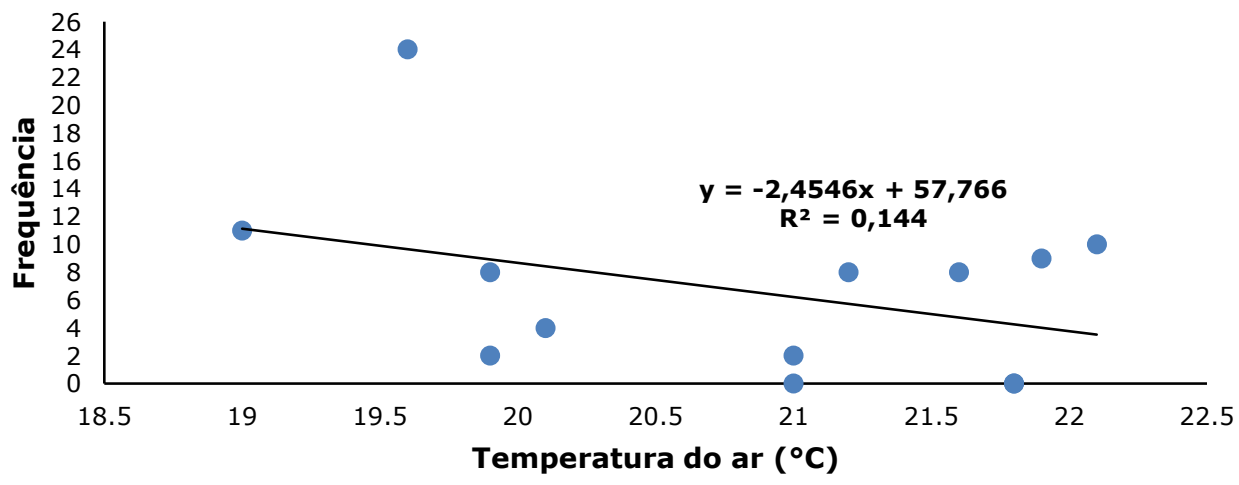

Fonte dos dados: Trabalho de campo. Organização: das autoras. 
A modelagem consiste em criar uma equação que expressa a relação matemática e estatística entre as categorias de uso da terra e a temperatura do ar, que são as variáveis do modelo. No exemplo destacado, a correlação global entre as duas variáveis, ou seja, o grau de relacionamento linear das variáveis foi de 0.47 , resultado que explica $47 \%$ da variabilidade dos dados. Desta forma, a ocorrência da ilha de calor no episódio analisado pode ser explicada com o uso da terra contribuindo com $47 \%$ nesta relação. Supõe-se que o relevo poderia contribuir também para a variação da temperatura do ar.

Individualmente, as categorias de uso da terra apresentam baixos coeficientes e isso demonstra a independência entre as variáveis (AMORIM et. al, 2015). As classes vegetação baixa (classe 1), urbana (classe 2) e a vegetação alta (classe 3 ) apresentaram coeficientes negativos sugerindo que estas classes apresentam menor peso para a estimação da temperatura do ar. Contudo, na análise conjunta dos parâmetros o coeficiente global aumenta (Quadro 2).

Quadro 2: Resultados da regressão múltipla, gerada a partir de dados da temperatura do ar relacionada com classes de uso da terra, dia 15 de julho de 2014, Rancharia (SP).

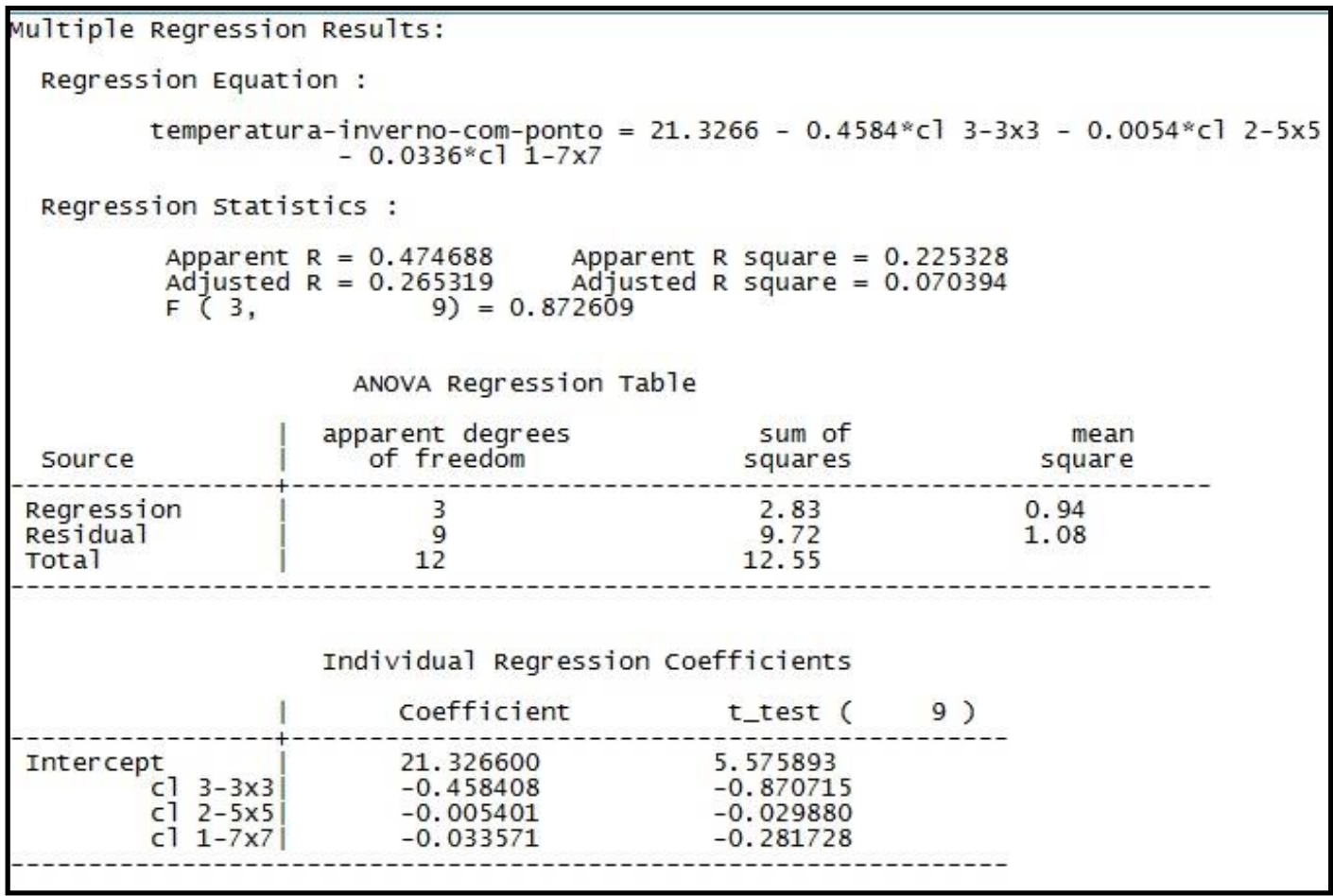

Mesmo com coeficiente de regressão reduzido, a equação gerada pelo modelo é capaz de espacializar a ilha de calor urbana em Rancharia definindo o centro urbano como o mais aquecido e a periferia com temperaturas amenizadas, aproximando-se do perfil clássico de ilha de calor de OKE (1974).

O episódio selecionado para a análise foi o de 15 de julho de 2014, em que houve simultaneidade entre os registros em campo e a tomada da imagem 
Landsat 7 na localidade, com a ressalva de que a tomada da imagem foi feita próximo às $10 \mathrm{~h} 00$ (hora local), enquanto que os dados primários foram registrados às 21 horas.

Neste dia, as condições atmosféricas na região de Rancharia (SP) estavam mediadas pela Massa Tropical Atlântica, ventos moderados, com velocidade de até $3 \mathrm{~m} / \mathrm{s}$ e orientação sudeste. Nestas condições de estabilidade atmosférica, a intensidade da ilha de calor atingiu $6^{\circ} \mathrm{C}$ (Figura 8).

A ilha de calor ficou delimitada na área urbana de Rancharia e no centro densamente construído se posicionou o seu núcleo, coincidindo com a intersecção das vias percorridas no transecto.

Áreas periurbanas e as áreas rurais próximas ocupadas por vegetação alta e baixa apresentaram as temperaturas mais amenas no intervalo de dados, enquanto que os solos expostos e a área urbanizada apresentaram temperaturas no intervalo entre 20 e $22^{\circ} \mathrm{C}$ comprovando que a categoria urbana exerce maior influência na formação da ilha de calor.

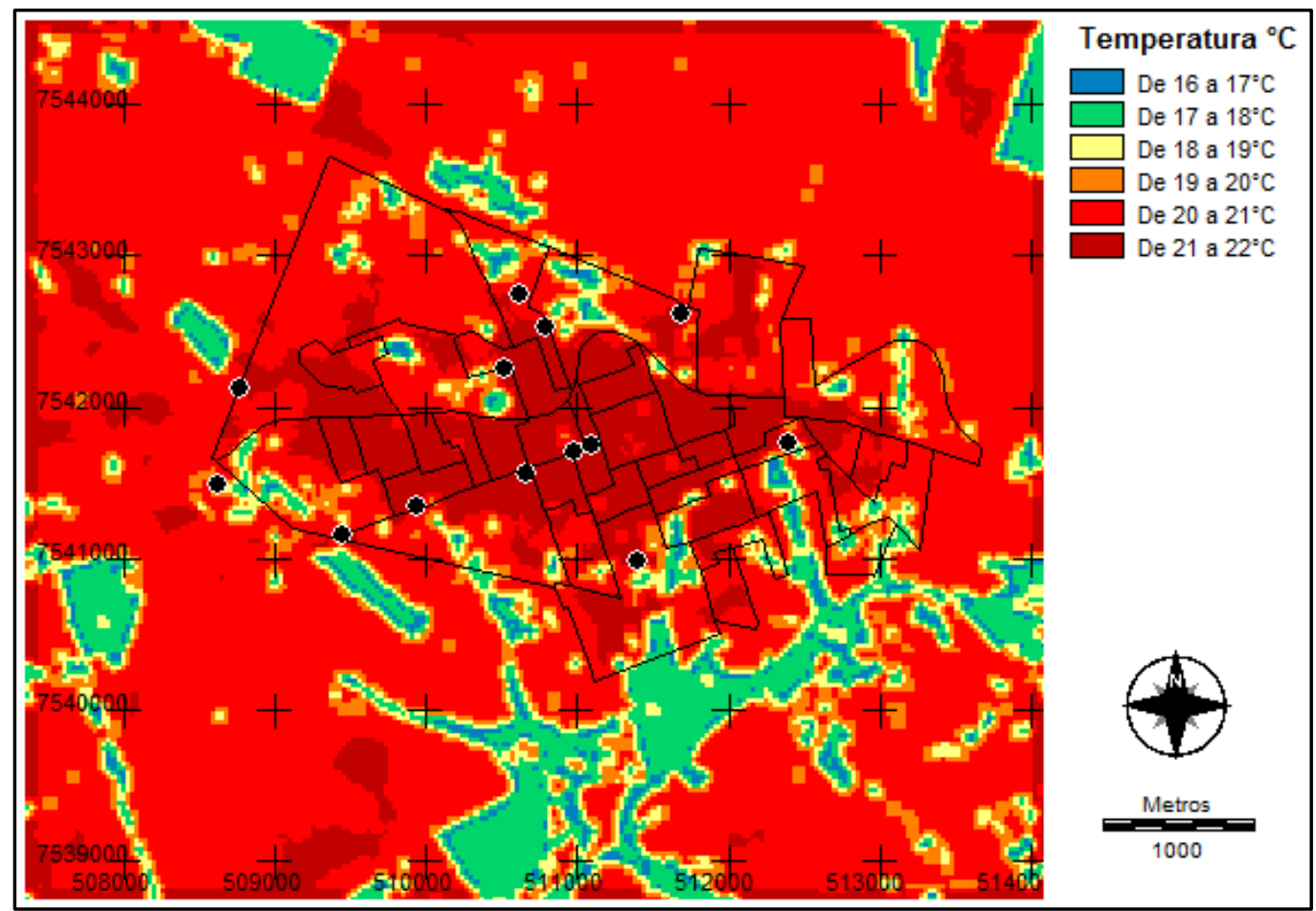

Figura 8: Modelagem da ilha de calor urbana, episódio de verão, Rancharia (SP), elaborada a partir da relação entre a temperatura do ar, classes de uso da terra e a imagem Landsat 7 do dia 15/07/2014. Fonte da imagem: <http://glovis.usgs.gov/> Elaboração: das autoras.

Em síntese, pode-se concluir que este procedimento é eficiente para a espacialização da ilha de calor, inclusive em pequenas cidades mostrando com maior detalhamento as superfícies urbanas que se caracterizam com maior aquecimento. Mesmo com coeficientes baixos e realizados em caráter de 
experimentação, posteriormente outros parâmetros tais como o relevo e a distância do centro poderão ser incorporados almejando melhores correlações estatísticas.

De posse desses resultados, medidas mitigadoras de amenização dos efeitos das ilhas de calor podem ser propostas ao poder público, tais como o ordenamento territorial e acréscimo de arborização urbana.

\section{CONSIDERAÇÕES FINAIS}

No presente trabalho objetivou-se a apresentação de procedimentos metodológicos para a análise e estudo do clima urbano em cidades de pequeno e médio porte, contribuindo para a discussão científica e acadêmica da temática, tendo as cidades interioranas de Cândido Mota (SP) e Rancharia (SP) como exemplos.

Destacaram-se procedimentos clássicos de investigação do clima das cidades, tendo a finalidade de demonstrar a evolução no tratamento desses dados, especialmente com o desenvolvimento dos SIGs.

Assim, foram abordadas metodologias empregadas no estudo das cidades apresentadas, sendo as mensurações da temperatura do ar realizadas através de pontos fixos e medidas móveis, a representação da temperatura superficial por meio de sensoriamento remoto e a modelização da temperatura urbana considerando-se as informações do uso e ocupação da superfície urbana, periurbana e rural. As formas de representações das informações obtidas através de trabalhos campo também foram elencadas nas cartas de isotermas, nos painéis espaçotemporais, nos perfis longitudinais e nos mapas.

Entretanto, outros procedimentos, não apresentados neste artigo, foram desenvolvidos para o estudo do clima urbano, a exemplo do trabalho de Katzschner (1997), que desenvolveu metodologia que consistiu na descrição qualitativa das características espaciais das áreas urbanas para o desenvolvimento de um sistema de classificação, a partir de uma avaliação bioclimática. Para isso, o autor se utilizou do índice de conforto PETphysiological equivalent temperature (KATZSCHNER, 1997). Tal metodologia consiste, portanto, na análise dos parâmetros urbanos como uso e ocupação do solo, estrutura urbana, topografia, densidade e altura das edificações, áreas verdes; no monitoramento das variáveis climáticas; e na análise do vento e do balanço de energia mediante a elaboração de um mapa-síntese das condições microclimáticas, de conforto térmico e da qualidade do ar para definição das áreas mais apropriadas aos tipos de uso do solo a serem propostos.

A diversidade de procedimentos metodológicos apresentados neste trabalho possui aplicabilidade em outros trabalhos de análise do clima urbano, particularmente das ilhas de calor urbanas, de acordo com o objetivo destes estudos e das características geoambientais e geourbanas da cidade investigada.

Entretanto, a adoção destes e outros procedimentos para o tratamento dos dados em climatologia urbana, dependem estritamente dos objetivos do trabalho. O monitoramento das ilhas de calor urbanas atmosféricas depende da observação empírica e da aquisição primária de dados em campo que se dá tanto pela rede meteorológica como por medidas móveis. O tratamento destes 
dados incorre em generalizações que podem ser minimizadas considerando-se o mapeamento sistemático da superfície como as cartas de uso da terra e os perfis longitudinais, complementares para a análise. Uma das alternativas para o tratamento dos dados tem sido a modelagem espacial, que apresenta maior confiabilidade na representação da ilha de calor e por relacionar a configuração espacial do fenômeno com as feições de uso e ocupação da terra.

No que tange à temperatura dos alvos para a identificação das ilhas de calor de superfície, esta análise depende da aquisição das imagens pelos satélites, da resolução temporal e espacial dos mesmos e da qualidade das imagens no que se refere à cobertura de nuvens. O uso das imagens dos satélites Landsat 5,7 e 8 são economicamente viáveis, pois são disponibilizadas gratuitamente, entretanto, as análises são restritas aos dias de passagem dos satélites. Outro fator limitante refere-se ao recorte da área de estudo, que se tratando de cidades pequenas, a resolução espacial das imagens muitas vezes não é adequada. Por último, os episódios de instabilidade atmosférica dificilmente podem ser monitorados devido à cobertura de nuvens.

\section{REFERÊNCIAS BIBLIOGRÁFICAS}

AMORIM, M. C. C. T. O Clima Urbano de Presidente Prudente/SP. 2000. 322 f. Tese (Doutorado em Geografia Física) - Faculdade de Filosofia, Letras e Ciências Humanas, Universidade de São Paulo, São Paulo.

- Intensidade e forma da ilha de calor urbana em Presidente Prudente/SP: episódios de inverno. Revista Geosul, UFSC - Florianópolis, v. 20, n. 39, p.65-82, jan./jun. 2005.

p. 71-

Climatologia e Gestão do espaço urbano. Mercator, número especial,

90, dez. 2010.

Aspectos conceituais e práticos da pesquisa em clima urbano. In: SILVA, C. A.; FIALHO, E. S. (org). Concepções e Ensaios da Climatologia Geográfica. E-book, 2012, p. 61-82.

AMORIM M.C.C.T., DUBREUIL V., QUENOL H., SANT'ANNA J.L. Características das ilhas de calor em cidades de porte médio: exemplos de Presidente Prudente (Brasil) e Rennes (França). Confins, Online, 7, 16p., 2009. Disponível em: Acesso em 31 Out. 2014

AMORIM, M. C. C. T.; DUBREUIL, V.; CARDOSO, R. S. Modelagem espacial da ilha de calor urbana em Presidente Prudente (SP) Brasil. Revista Brasileira de Climatologia, v. 16, p. 29-45, 2015. 
ARAÚJO, R. R. O processo de urbanização na produção do clima urbano de São Luiz/MA. 2001. 217f. Dissertação (Mestrado em Geografia) - Faculdade de Ciências e Tecnologia, Universidade Estadual Paulista, Presidente Prudente.

BRANDÃO, A. M. P. M. O clima urbano na cidade do Rio de Janeiro. In: MONTEIRO, C. A. de F.; MENDONÇA, F. Clima Urbano. São Paulo: Contexto, 2009. p. $121-153$.

CARFAN, A. C. Análise do conforto térmico em áreas abertas no município de Ourinhos-SP. 2011. 168f. Tese (Doutorado em Ciências - Geografia Física) Faculdade de Filosofia, Letras e Ciências Humanas, Universidade de São Paulo, São Paulo.

DUBREUIL V., DELAHAYE C., LE STRAT A. Dynamiques d'occupation et d'utilisation du sol et leurs impacts climatiques au Mato Grosso, Brésil. Confins, online, 10, 2010 Disponível em : Acesso em 31 Out. 2014.

DUMKE, E. M. S. Clima urbano/conforto térmico e condições de vida na cidade - uma perspectiva a partir do aglomerado urbano da região metropolitana de Curitiba (AU_RMC). 2007. Tese (Doutorado em Meio Ambiente e Desenvolvimento) - Universidade Federal do Paraná, Curitiba

FERNÁNDEZ GARCÍA, F. Manual de climatología aplicada: clima, medio ambiente y planificación. Síntesis, 1996.

FERREIRA, C. De C. M. Aplicação da lógica nebulosa (fuzzy cluster) na definição de unidades climáticas: estudo de caso na bacia do Rio ParaibunaMG/RJ. Revista Brasileira de Climatologia, v.10, p.85-97, jan/jun, 2012.

Foissard, X. ; Quenol, H. ; Dubreuil, V. Analyse et spatialisation de l'ilot de chaleur urbain dans I'agglomeration Rennaise. In: XX VIème Colloque de I'Association Internationale de Climatologie, 2013, Cotonou, Bénin, p. 242-247.

FRASCA TEIXEIRA, D.C. O clima urbano de Rancharia (SP). 2015. $217 \mathrm{f}$. Dissertação (Mestrado em Geografia). Faculdade de Ciências e Tecnologia de Presidente Prudente, Universidade Estadual Paulista, Presidente Prudente, 2015.

FRASCA TEIXEIRA, D. C. F.; AMORIM, M.C.C.T.; DUBREUIL, V. Modelagem da ilha de calor urbana para cidade pequena (Rancharia-SP) a partir de imagens do satélite Landsat 7 e de medidas da temperatura do ar. In: XVII Simpósio 
Brasileiro de Sensoriamento Remoto. 2015, João Pessoa. Anais... João Pessoa, 2015, p. 1-8.

GARTLAND, L. Ilhas de calor: como mitigar zoas de calor em áreas urbanas. Tradução Silvia Helen Gonçalves. São Paulo: Oficina de Textos, 2010.

LANG, S.; BLASCHKE, T. Análise da Paisagem com SIG. Tradução: Hermann Kux. São Paulo: Oficina de textos. 424 p.

MENDONÇA, F. A. O clima e o planejamento urbano de cidades de porte médio e pequeno. Proposição metodológica para estudo e sua aplicação à cidade de Londrina/PR. 1994. Tese (Doutorado em Geografia Física) - Faculdade de Filosofia, Letras e Ciências Humanas, Universidade de São Paulo, São Paulo.

JENSEN, J. R. Sensoriamento Remoto do ambiente: uma perspectiva em recursos terrestres. $2^{a}$ ed. São José dos Campos: Parenteses, 2009.

LÓPEZ GÓMEZ, A. L. (Cood.), FERNÁNDEZ GARCÍA. F.; ARROYO, F.; VIDE, J. M.; CUADRAT, J. M. El clima de las ciudades españolas. Madrid: Catedra, 1993.

KATZSCHNER, L. Urban climate studies as tools for urban planning and architecture. In: Encontro nacional de conforto no ambiente construído, 4, 1997, Salvador. Anais... Salvador: FAUFBA/LACAM; ANTAC, 1997, p. 49-58.

KATZSCHNER, L ; MULDER, J. Regional climatic mapping as a tool for sustainable development

Journal of Environmental Management, Apr 2008, Vol.87(2), pp.262-267.

MONTEIRO, A. O clima urbano do Porto: contribuição para a definição das estratégias de planejamento e ordenamento do território. Porto: Fundação Calouste Gulbenkian, Junta Nacional de Investigação Científica e Tecnológica, 1997. 486p.

MONTEIRO, C. A. F. Teoria e Clima Urbano. São Paulo: IGEOG/USP, 1976. (Série Teses e Monografias).

LOURENÇO, R. W.; LANDIM, P. M. B. Análise de regressão múltipla espacial. UNESP/Rio Claro, IGCE, DGA, Lab. Geomatemática. Texto Didático 13, 34 pp. 2004. 
OKE. T. R. Boundary Layer Climates. 2. ed. London: Methuem \& Ltd. A. Halsted Press Book, John Wiley \& Sons, New York, 1987, 372p.

Review of urban climatology: 1968-1973. Geneva: Wold Meteorological Organization, 1974 (WMO Technical note, n. 134).

. Siting and exposure of meteorological Instruments at urban sites. In: NATO/CCMS International Technical Meeting on Air Pollution Modelling and its Application, 27., 2004, Canadá: Banff, 2004, p. 1-14. Disponível em: <http://urbanclimate.com/ITM04-Oke.pdf>. Acesso em: 26 set. 2014.

ORTIZ, G. F. O clima urbano de Cândido Mota: análise do perfil térmico e higrométrico em episódios de verão. 2012. 163f. Dissertação (Mestrado em Geografia) - Universidade Estadual Paulista, Faculdade de Ciências e Tecnologia. Presidente Prudente-SP.

ORTIZ PORANGABA, G. F. O clima urbano das cidades do interior do estado de São Paulo: uma análise do campo térmico de Assis, Cândido Mota, Maracaí e Tarumã. 2015. 354f. Tese (Doutorado em Geografia) - Faculdade de Ciências e Tecnologia, Universidade Estadual Paulista, Presidente Prudente.

PITTON, S. E. C. As cidades como indicadores de alterações térmicas. 1997. 272p. Tese (Doutorado em Geografia Física) - Faculdade de Filosofia, Letras e Ciências Humanas, Universidade de São Paulo, São Paulo.

REN, C.; NG, E.Y.-Y.; KATZSCHNER, L. Urban climatic map studies: A review. International Journal of Climatology, December 2011, Vol.31(15), pp.22132233.

REN, C. ; SPIT, T. ; LENZHOLZER, S. ; YIM, H.L.S. ; VAN HOVE, B.H. ; CHEN, L. ; KUPSKI, S. ; BURGHARDT, R. ; KATZSCHNER, L. Urban Climate Map System for Dutch spatial planning. International Journal of Applied Earth Observation and Geoinformation, 2012, Vol.18(1), pp.207-22.

UGEDA JUNIOR, J. C. Clima urbano e planejamento na cidade de Jales/SP. 2012. 383 f. Tese (Doutorado em Geografia) - Faculdade de Ciências e Tecnologia, Universidade Estadual Paulista, Presidente Prudente.

SANT'ANNA NETO, J. L. Ritmo climático e a gênese das chuvas na Zona Costeira Paulista. 1990. 156f. Dissertação (Mestrado em Geografia) Universidade de São Paulo, Faculdade de Filosofia, Letras e Ciências Humanas 
YAMAMOTO, J.K.; LANDIM, P. M. B. Geoestatística: conceitos e aplicações. São Paulo: Oficina de textos, 2013.

\section{AGRADECIMENTOS}

Ao apoio financeiro concedido pela Fundação de Amparo à Pesquisa do Estado de São Paulo - FAPESP (Processos: 2012/00039-1 e 2013/02081-8). 